\title{
GIL HERNÁNDEZ, António. Temas de linguística política. Seguidos dum avanço de Temas de política linguística. Leves reflexóes sobre política nacional "española”. Santiago de Compostela: Associação de Amizade Galiza- Portugal, 2006.
}

Álvaro J. Vidal Bouzon Universidade de Nottingham, Reino Unido

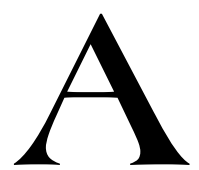

ntónio Gil Hernández é um mestre. No sentido

que George Steiner tem elogiado e de cuja função societária tem, acaso, nos seus textos, levantado formosíssima ata de defunção. Mas António Gil Hernández é, antes de mais e sobretudo, um pensador de primeira linha sobre as condições sociolinguísticas e glotopolíticas em que a Comunidade lusofónica da Galiza vive. Ou sobrevive. Ou resiste, até. Sobreviver a quê?, resistir contra quem? são, aliás, perguntas para cuja resposta os textos de Gil Hernández se têm configurado como inestimável e imprescindível ferramenta crítica. Até ao ponto de não poucos dos argumentos e conceitos por ele (re)eleborados ao longo das últimas três décadas serem tão rastejáveis quanto a sua origem indecentemente silenciada na produção daqueles que militam em posições teóricas e políticas contrárias. Porque a esclarecida dimensão política (em sentido estritamente filosófico e, pois, não isento de uma certa carga aporética) do seu tratamento do cultural, linguístico e literário é o que tem colocado a obra de António Gil na posição de centralidade que lhe corresponde no panorama 
inteletual da Galiza. ${ }^{1}$ Posição, aliás, contra todas as (re)pressões por parte de uma oficialidade galegoespanbola cujos pressupostos programáticos, princípios ideológicos e práticas discriminatórias têm sido objeto do afiado olhar de Gil Hernández, por exemplo, no seu livro Silêncio ergueito (Sada: do Castro, 1986), do qual este que nos ocupa é continuador e aprofundador. ${ }^{2}$ Um olhar, claro, assente num respeito profundo pela comunidade de língua, de toda a língua. Um olhar, assim, articulado sobre o paciente labor de restauração do sentido próprio das palavras, das expressões, dos textos; resgatandoos, desta forma, das deslocações semânticas e pragmáticas a que têm sido submetidos no território dialético e retórico do combate político. Um olhar, por fim, do qual faz parte essencial o trabalho que António Gil tem despregado nas organizações sociais de caráter cultural lusófono dentre as que merece agora destacar-se aquela que publica o presente volume, a Associação de Amizade GalizaPortugal.

No "Prologuinho petiscante" com que o livro se inicia (e que constitui, assim mesmo, uma magnífica introdução à linguística social) Gil Hernández se põe a tarefa de "Pensar a Lusofonia". Quer dizer, de delinear a sua definição conceptual e de apontar à sua realização universalizante. Porque será este potencial universalizador, e humanista, que equipara as comunidades lusofónicas com as doutras línguas, o que alente a sua análise. Potencial, porque Gil Hernández sabe da persistente tendência no seio da Lusofonia a efetivar umas práticas que incidem mais nos traços diferenciais do que no por ele qualificado de "discurso da/de unidade"; ao contrário do dominante na Anglofonia, na Fracofonia ou na Hispanofonia.

\footnotetext{
${ }^{1}$ Assim, em português; e não, em espanhol, Galicia: o livro que resenhamos indica as fragmentações glóssicas da população dessa Comunidade Autónoma do Reino de Espanha e fará uso marcadamente diferencial de ambos os "seus" nomes na consciência de que tudo, em termos identitários, se joga, primeiro, na perentória escolha de um deles e de que ambos encarnam, até certo ponto, os agónicos extremos do conflito do qual este livro a um tempo dá conta e participa.

${ }^{2}$ Em relação à fundante consideração desigual da comunidade lusófona da Galiza, e dos direitos dos lusófonos galegos, se comparada com a hispanófona, e os direitos dos hispanófonos galegos ou não, por parte do quadro legal espanhol pode ler-se especialmente o "Capítulo hesitante: os Direitos Humanos [desde a Galiza]" de Temas de linguística política.
} 
Neste sentido, a Lusofonia acolheria uma certa pulsão fracturante na que o conflito linguístico em que a comunidade lusofónica da Galiza se acha encontraria espelho perfeito. Pulsão, aliás, segundo o autor indica, claramente suicida e contra a qual seria instrumento privilegiado a promoção do espírito que coalhou no Acordo Ortográfico da Língua Portuguesa de 1990, ${ }^{3}$ reconhecedor da variedade sob a cobertura da unidade da língua e não vice-versa. Espírito, aliás, do que foram partícipes diferentes vultos inteletuais lusófonos como Celso Cunha, Antônio Houaiss, Agostinho da Silva ou Manuel Rodrigues Lapa; todos eles cônscios do caráter lusofónico das comunidades de fala galega inclusas no Reino de Espanha (no livro podemos achar alusões ou referências explícitas a muitos desses autores assim como um esclarecedor estudo das ideias de Rodrigues Lapa sobre a recuperação literária do português da Galiza).

É, pois, a fundamentação e reivindicação da condição luso-fónica da Galiza e o pensar as condições da sua pervivência o foco deste texto. $\mathrm{Na}$ perspetiva, sempre, da solida- riedade transnacional que ela requer. $\mathrm{E}$ a isso procede trás estabelecer uma inicial cartografia ou sistematização das diferentes circunstâncias e diversas posições (nomeadamente glotopolíticas e relativamente ao seu papel no mundo lusófono) em que os por António Gil denominados "sete+um+um" (Portugal, Brasil, Angola, Moçambique, Cabo Verde, Guiné-Bissau, São Tomé e Príncipe, Timor-Lorosae e Galiza) se acham. São interessantes, neste ponto, a sistematização de semelhanças e diferenças entre as diferentes regiões estabelecida por Gil Hernández e "o papel dirigente" da Lusofonia, como "primus interpares", atribuído ao Brasil.

Como é evidente não são estes Temas de linguística política uma exposição restritamente filológica cujo intuito seria, mais uma vez, demonstrar que as falas galegas são aind $^{4}$ parte do diassistema linguístico internacionalmente conhecido pelo nome de português. Que o "galego" é "português" é posição teórica tradicional da linguística em geral e da romanística em particular. É aqui onde a qualificação como política da linguística

${ }^{3}$ Em cuja elaboração como parte da delegação da Galiza ele próprio tinha participado e que usa desde então na redação dos seus escritos.

${ }^{4}$ Apesar do grau de deturpação em que se acham por estarem em maior ou menor medida reprimidas no longo processo em curso de imposição, socialização e normalização da língua espanhola na Galiza. 
do título cobra todo o seu sentido. Pois de uma específica intervenção política há que dar conta para explicar a inovadora posição segundo a qual aquelas falas deixaram $j a ́$ de ser português e passaram a se constituir numa "nova língua": "o galego". E essa intervenção política é a que efetiva o projeto de construção (e unificação) nacional espanhola contra os (possíveis) projetos de construção nacional da Galiza (entre outros). Repare-se na desigual distribuição do número dos termos: "o projeto" vs. "os (possíveis) projetos". Porque não é a de Gil Hernández uma redutora oposição binária: o realmente trágico da situação que descreve é que a parte mais politicamente visível do nacionalismo galego após a formal restauração democrática no Reino de Espanha em 1978 tem assumido em boa medida as noções ideológicas que reduzem a língua (inter)nacional dos galegos (o português) a uma "língua própria" encerrada dentro de Espanha, assumindo umas regras de correção idiomática (padronização e normação) decalcadas e subsidiárias das do espanhol. A cifra que exprime de modo imediato para todos os utentes da língua (incluídos os doutras regiões da Lusofonia) os efeitos desta situação é a imposição da ortografia espanhola para a escrita do português da Galiza, o que, como assinala Gil Hernández, de fato o amputa simbolicamente e materialmente da área de comunicação lusófona para o incluir, com funções diminuídas, na hispanófona. Ou, por outros termos, faz possível a entrada na Lusofonia dos produtos culturais "em galego" só sob a condição de tradução e vice-versa. Esta situação tem objetivamente contribuído para acelerar o que António Gil qualifica como "processo de substituição linguística do português galego pelo espanhol". Portanto, para travar (e inverter, mesmo) tal processo haverá, primeiro e como conditio sine qua non, de ser restaurado o correto ("natural", inclusive, segundo o autor) critério de correção (ou, mais tecnicamente, nos seus termos, "correlacionamento diglóssico") interior à comunidade linguística a que as falas galegas pertencem. ${ }^{5}$

\footnotetext{
${ }^{5}$ É o que se explora nos intitulados "Capítulo fundamental: conceito de diglossia" e "Capítulo fiducial: propostas diglóssicas de futuro possível". Aliás, estes capítulos vêm completar a essencial intervenção teórica de Gil Hernández, desde fins dos oitenta do século passado, na delimitação deste conceito formulado inicialmente por Charles A. Ferguson e da sua manipulação e/ou pertinência para a categorização do conflito linguístico na Galiza espanhola. O próprio livro,
} 
Contudo, o realmente crucial, do ponto de vista político, na articulação teórica de Temas de linguística política, a questão que percorre todo o livro, é a conceptualizão crítica da função dos agentes cuja subjetividade se configura (em feed-back) na conflituosa situação glotopolítica da Galiza. Aqueles aos que António Gil refere quer com o termo abstrato de "notabilidade" quer com o mais concreto de "os notáveis" (para depois estabelecer uma série de subcategorizações dependentes da lealdade nacional dos mesmos). Termos, ambos, que aludem a algo mais que a umas elites, ou que ao gramsciano inteletual orgânico e que nos conetam de imediato com o início mesmo da Modernidade pois coalham em redor dos processos revolucionários (dividores) de 1789 e da construção correlativa da categoria de "povo". Assim, ao ver de Gil Hernández, haveria de dar-se, em toda a sociedade "normal" (e o livro avança uma definição de em que consiste a "normalidade" de uma sociedade moderna), uma relação dialética entre esses dois pólos societários de modo aos notáveis serem, de fato, por sua expressão, "cabeça de povo" e, o povo, efetivamente, "povo cabeçado". O caráter defeituoso da seção dominante de uma possível notabilidade galega fica, a seguir, imediatamente descrito e explicado. Incapaz de notar o povo galego quanto galego ${ }^{6}$ e, em reciprocidade, serpor ele notado: a submissão daqueles que com maior visibilidade aspiram a ser notáveis da Galiza aos programas ideológico-nacionais desenhados e implementados pela notabilidade espanhola (que parace por vezes devir modelo a contrario) é posta em evidência com profusão de exemplos (práticos quanto textuais). E a significativa função da notabilidade lusófona dos outros territórios de língua portuguesa na ajuda da ameaçada lusofonia da Galiza é, assim mesmo, conflituosamente caraterizada. Por fim, o fundamental papel jogado historicamente pela notabilidade na constituição do imaginário nacional através do instrumento linguístico e, até, correlativamente, no estabe-

no "avanço de Temas de política linguística" com que conclui, anuncia uma dedicação com maior pormenor ainda em volume certamente complementar deste e de futura publicação.

${ }^{6}$ Lusófono, pois: a centralidade da língua na definição da nação galega é inquestionada pelo galeguismo histórico e o nacionalismo galego politicamente organizado. 
lecimento das normas mesmas de correção idiomática, é perspetivado num bloco de capítulos dedicados ao estudo social do fato literário ${ }^{7}$ que constituem, assim mesmo, uma magnífica introdução à teoria da literatura e que são usados como conjunto de exempla e fundamentação programática para a ainda incipiente notabilidade da Galiza. A este respeito, resultam de especial interesse, sobretudo para a Lusofonia europeia, os estudos sobre Eça de Queirós, Fernando Pessoa e o poeta galego Manuel Maria.

Apesar da explícita preocupação com a dimensão utópica do projeto de socialização (na sociolinguística galega dito de "normalização") do português da Galiza que surge em várias ocasiões no livro (de modo mais concentrado no "Capítulo chointe ou abrideiro: singelamente lírico"), o discurso de Gil Hernández está fortemente enraizado numas coordenadas em que predomina a paciente desconstrução da forma política da modernidade por excelência (o Estado-Nação), enfrentando-se, olhos bem abertos, aos seus modos de conformação do social e questionando o que cada um dos termos da categoria com que conhecemos aquela forma política ("Estado" e "Nação") faz ao outro e incorpora ao ou tira do "novo" termo. E é aí, muito precisamente, onde a questão essencial reverbera: porque e como se tem tornado a Nação, sob a sua constrição e/ou alargamento estatal, na forma privilegiada e politicamente determinante de "segurar" comunidade, e comunidade sobretudo linguística, na nossa era?

\footnotetext{
7 Assim em "Capítulo explorante: diglossia, normalidade, literariedade vanguardista", "Capítulo estimulante: língua literária e identidade nacional", "Capítulo caraterizador: língua literária ou nacional", "Capítulo prometente: concepções "literário-nacionais"” e "Addendum".
} 